\title{
The Compliments and the Compliment Responses Used by the Characters in What Women Want
}

\author{
Nani I. Tiono, Irene Nova \\ English Department, Faculty of Letters, Petra Christian University, \\ Surabaya, East Java, Indonesia \\ e-mail: nitiono@peter.petra.ac.id, irene_nova@yahoo.com
}

\begin{abstract}
This study is aimed to reveal the type of compliments and the compliment responses produced by the main female character that is superior and on the responses produced by the main male character that is subordinate in the movie What Women Want. Finally, the research came up with the result that social status and gender did not always influence the way the main female superior character gave compliments toward the main male subordinate character and vice versa.
\end{abstract}

Key words: compliments, compliment responses, gender, social status

Compliment is an expression of adoring, praising or admiring toward someone. It can happen between people who have different social status, gender and age. Because of the differences, the act of giving compliments toward someone may vary. Wolfson (1978) \& Manes (1980), for example, conducted their research on compliments among middle class Americans. They found out that women were frequent recipients possession regardless of their status. It means that women frequently received compliments without considering their status. In contrast, men who had higher status than women rarely received compliment that was related to their performance and their ability. Besides the acts of giving compliments that may vary, the expression of the compliment responses also has enormous variation because of social status, age and gender differences of the participants.

According to Wolfson \& Manes (1983), as cited by Herbert (1989), based on the major topics of the compliments, compliments are divided into three categories. In relation to the topic, compliments fall into Compliment on Appearance, Compliment on Skills/ Abilities and Compliment on Possessions.

Compliment on Appearance is a compliment given for someone's appearance. The compliments are usually about the appearance of the addressee, such as the clothes and the hair of the addressee. Compliments 
on someone's appearance are the most common type of compliments, for example, "Your blouse looks beautiful!!"

Compliment on Skills/Abilities is a compliment given as the quality of something produced through the addressee's skill or effort like a well done job, a skillfully played game, a good meal, etcetera, for example, "That's a very nice cake you made!"

The third category is Compliment on Possessions. This category is a compliment that is given for someone's possessions. The words 'like' or 'love' are used ninety percent of the time in the type of Compliment on Possessions, for example, "I really love your car!"

Besides the type of Compliments from Wolfson and Manes (1983), Herbert (1989) divided the type of Compliment Responses into twelve categories. The classification and the examples are shown below:

1. Appreciation Token

This category conveys the meaning of acceptance of the compliment whether it is verbal or nonverbal. The addressee answers by using a gesture such as nodding head or saying "thank you", for example, "Thanks", “Thank you”, [nod].

2. Comment Acceptance

In this category, the addressee accepts the complimentary force and offers a relevant comment on the appreciated topic, for example, "Yeah, it's my favorite too."

3. Praise Upgrade

The addressee accepts the compliments and asserts that the compliment force is insufficient, for example, "Really brings out the blue in my eyes, doesn't it?"

4. Comment History

The addressee offers a comment (or series of comments) on the object complimented, but the comment is shifted the force of the compliment from the addressee, for example: "I bought it for the trip to Arizona"

5. Reassignment

In this type, the addressee agrees with the compliment assertion, but the complimentary force is transferred to some third person or to the object itself, for example, "My brother gave it to me"

"It really knitted itself"

6. Return

In this type, the compliment is shifted (or returned) to the first speaker, for example, "So's yours" 


\section{Scale Down}

The addressee disagrees with the complimentary force, pointing to some flaw in the object or claiming that the praise is over stated, for example: "It's really quite old"

8. Questioning

The addressee questions the sincerity or the appropriateness of the compliment, for example, "Do you really like them?"

9. Disagreement

The addressee asserts that the object complimented is not worthy of praise, the first speaker's assertion is error, for example:
A. "You look good and healthy"
B. "I feel fat"

10. Qualification

This type is weaker than disagreement. The addressee merely qualifies the original assertion, such as, but, well, though, and the use of than in order to show degree of comparison, for example, "It's all right, but Len's is nicer"

11. No Acknowledgement

The addressee gives no indication of having heard the compliment: the addressee either responds with an irrelevant comment or gives no response. Addressee can shift topic or keep quiet, for example:
A. "You did a good job!"
B. No response

12. Request Interpretation

The addressee, consciously or not, interprets the compliments as a request rather than a simple compliment, for example, "You wanna borrow this one too?"

Compliment is often found in the conversation of everyday life within people in the society. People give compliment in order to establish and maintain a good social relationship. Whenever compliment is uttered, there must be the reply as the response toward the compliment. It is generally agreed that the polite thing to do is to accept compliment. In practice, however, compliments are not always accepted. Pomerantz (1978) argued that this was because compliments place addressees in a difficult position: they had to juggle two conflicting conversational rules: 'Agree with the speaker' and 'Avoid self praise'. The conversation that consists of the act of complimenting could happen in the movie considering that movie is 
made based on what happens in real daily life conversation. For that reason, the object of investigation in this study was taken from a movie entitled What Women Want.

What Women Want is a drama comedy film that tells about a divorced man with one daughter, named Nick. He worked in an advertisement company and his manager was a smart and talented woman, named Darcy. He used to be a man who did not understand what women wanted; he did not understand what his daughter wanted, what his manager wanted and what many women in his office wanted. That was the reason why many women in his office thought that Nick was a boring person and Alex, his daughter, did not have a close relationship with him. However, one day he had an accident and after the accident, surprisingly, he could read what women thought about; he could read what in women's mind. Because of that, he could be the best father for his daughter and he could get Darcy's love.

The study analyzed What Women Want because in this film there was uniqueness in the act of complimenting related to the social status and gender differences of the characters. In this case, social status and gender differences influenced the way the characters gave compliment and also responded to it. In this film, the woman had a higher status than the man; she became the boss while the man was the employee. Most of the setting in this film told what happened in the office, so the communication at work including the compliments between the participants who had different social status and gender was often found in every scene.

\section{METHODOLOGY}

This research was qualitative descriptive in which the data were the utterances that contained compliments produced by the main female character (Darcy) and the responses produced by the main male character (Nick).

Due to the focus of this study, that is, on the type of compliments produced by the main female character (Darcy) and the type of compliment responses produced by the main male character (Nick), the procedures of the analysis was started by collecting the compliments and the compliment responses produced by the main characters. The next step was tabulated the compliments into one table and the compliment responses into another table. Then, the utterances were analyzed based on the type of compliments 
according to Wolfson and Manes (1983) and the type of compliment responses according to Herbert (1989). After that, the frequencies of each type of compliments and the compliment responses were counted and classified in the table of findings. Finally, the types of compliments and the compliment responses produced by the characters were revealed by determining the most frequent types produced.

\section{FINDINGS AND DISCUSSION}

The findings showed that there were two types of compliments produced by Darcy as female superior in the conversation: Compliments on Skills/Abilities and Compliments on Personality Traits. Compliments on Skills/Abilities were a type of compliment that occurred the most frequently. Moreover, the findings for the kinds of compliment responses produced by Nick as subordinate showed that there were five kinds of compliment responses. Besides, the one that occurred the most frequently was No Acknowledgement type.

\section{Types of Compliments}

From the movie "What Women Want", it was found that the main female character as superior often gave compliments to the main male character as subordinate. There were two types of compliments produced by Darcy as female superior, that is, compliments on skills or abilities and compliments on personality traits. The finding of the two types of compliments was shown in Table 1.

Table 1. The Percentage of Compliments by Female Character (Darcy)

\begin{tabular}{lcc}
\hline \multicolumn{1}{c}{ Types of Compliment } & $\mathbf{n}$ & $\mathbf{\%}$ \\
\hline Appearance & 0 & 0 \\
Skills/Abilities & 11 & $57,9 \%$ \\
Possessions & 0 & 0 \\
Personality & 8 & $42,1 \%$ \\
\hline \multicolumn{2}{c}{} \\
\hline
\end{tabular}

In table 1, there were $57,9 \%$ of Compliments on Skills/Abilities produced by Darcy in the conversation with Nick. One of the Compliments on Skills/Abilities could be seen in the conversation between Nick and Darcy as follows: 
NICK:

Yeah? Hmm. And you know... ... why don't you get them to try it in Black and white? Might punch it up a little...

NICK:

What, did you say something?

\section{DARCY:}

No. I just swear I was thinking the exact same thing.

NICK:

Were you?

DARCY:

Black and white could really help. Good idea, Nick.

Nick and Darcy were having a conversation about a design of a picture. Darcy thought that Nick's idea was a great idea, so she appreciated Nick's idea. The reason why Darcy as a female superior gave compliment on skills or abilities toward Nick who was her employee was to give a reward or appreciation for Nick's idea.

Based on the analysis, it was found that there was another type of compliment that was not the type introduced by Herbert. This type was Compliment on Personality. This type of compliment is a type of compliment on someone's personality, for example "Good Boy" and "You're so sweet". The writer found that there were 42, $1 \%$ of Compliments on Personality uttered by Darcy as female superior toward Nick as male subordinate. The conversation is as follows:

DARCY:

You are full of surprises.

NICK:

Yeah.

One of the Compliments on Personality can be seen in the conversation mentioned above. Nick and Darcy were chatting in Darcy's office since they overworked. Compliment on personality produced by Darcy toward Nick was when she said "You are full of surprises". It was a Compliment on Personality because Nick was able to deliver a joke that could make Darcy feel amused because of his humorous personality.

\section{Types of Compliment Responses}

In the conversation, when people give compliment to the addressee, they would also receive the response. Among English speakers, it is 
generally agreed that the polite thing to do is to accept the compliment. In practice, however, compliments are not always accepted. People have to juggle two conflicting conversational rules: 'Agree with the speaker' and 'Avoid self praise'. From the movie, it was found that there were five types of compliment responses used by Nick as the main male character. The result can be seen in Table 2 .

Table 2. The Percentage of Compliment Responses by Male Character (Nick)

\begin{tabular}{lcc}
\hline \multicolumn{1}{c}{$\begin{array}{c}\text { Types of Compliment } \\
\text { Responses }\end{array}$} & $\mathbf{n}$ & $\mathbf{\%}$ \\
\hline Appreciation Token & 1 & $6,25 \%$ \\
Comment Acceptance & 0 & 0 \\
Praise Upgrade & 0 & 0 \\
Comment History & 1 & $6,25 \%$ \\
Reassignment & 0 & 0 \\
Return & 4 & $25 \%$ \\
Scale Down & 2 & $12,5 \%$ \\
Question & 0 & 0 \\
Disagreement & 0 & 0 \\
Qualification & 0 & 0 \\
No Acknowledgement & 8 & $50 \%$ \\
Request Interpretation & 0 & 0 \\
Others & 0 & 0 \\
\hline \multicolumn{2}{c}{} \\
\hline
\end{tabular}

Appreciation Token is one of the types of compliment responses that refers to the acceptance of the compliment by saying "thanks" and "thank you" or nodding head. The example of the conversation is shown below:

DARCY:

You are full of surprises.

NICK:

Yeah.

In that conversation, Nick accepted Darcy's compliment on his personality by saying "yeah". Nick's statement belongs to the Appreciation Token because he was saying "yeah" while he was nodding his head. Nick showed his agreement to Darcy's compliment by nodding his head. 
The second type found was Comment History with the percentage of $6,25 \%$. Comment History is a type of compliment response that refers to the acceptance of the compliment, for example:

DARCY:

No, I mean...

DARCY:

....really, really great.

NICK:

I haven't' had this much fun making out since... I've never had this much fun making out.

The Comment History response produced by Nick as subordinate can be seen in the conversation above. Nick and Darcy were hanging out together in a bar at night. After they were kissing, Darcy gave Nick compliment that Nick was such a good kisser. Nick was giving an Appreciation Token response toward Darcy's compliment. Nick was easily accepting compliment from Darcy. Moreover, he responded by telling his personal experience to Darcy.

Another type found was Return, that is, the type of compliment responses in which the addressee agrees with the compliment assertion, but returns the complimentary force to the speaker. It was found that there were $25 \%$ of Return responses produced by Nick, for example:

DARCY:

Why are you not the happiest guy in Chicago right now? You just did so great.

NICK:

Naw, naw. I didn't do so great. We did so great. No, actually, you did so great.You.

The conversation above is one example of Return. In this situation, Nick and Darcy were at the office. Darcy tried to amuse Nick by saying "Why are you not the happiest guy in Chicago right now? You just did so great." Firstly, Nick did not accept the compliment by saying "Naw, naw. I didn't do so great." However, after that Nick agreed with Darcy's compliment by returning the complimentary force to Darcy. He said "No, actually, you did so great".

The next type was Scale Down. It is a type of compliment response when the addressee disagrees with the complimentary force, claiming that the praise is over stated. The conversation is mentioned below: 


\section{DARCY:}

Yes. That's exactly what I wanted to say. Sometimes I think you're a bit of a mind reader.

NICK:

But I don't have to be a mind reader with you because you always say what you think.

The conversation above is one example of Scale Down. In this situation, Nick and Darcy were going out together. Darcy gave Nick compliment by saying “....I think you're a bit of a mind reader.” Nick disagreed with Darcy's compliment by saying "But I don't have to be a mind reader with you because you always say what you think." Nick did not accept the compliment because he avoided self praise.

The last type of Compliment Responses produced by Nick was No Acknowledgement type. This type occurred the most frequently among the other types of compliment responses. According to Herbert (1989), No Acknowledgement is one of the types of compliment responses when the addressee gives no indication of having heard the compliment. "The addressee either responds with an irrelevant comment (i.e. topic shift) or gives no response" (p. 208), for example:

\section{DARCY:}

Um, what's good about your idea... ....is that you're looking at Advil from a woman's point of view. Um, I don't think Advil will go for it and I'm pretty sure every woman in America will hate it. Other than that, I thought it was great. So you're on the right track. Hang in there.

\section{DARCY:}

Go ahead.

The conversation above happened at the office. Nick and Darcy were having a meeting with the other employee. Then, in the meeting, Nick was giving his creative idea about Advil, a medicine that women usually used. Darcy showed her disagreement by giving a compliment first, then she uttered her idea although after that she gave a compliment again to emphasize that she appreciated Nick's idea. However, Nick did not give a response toward Darcy's compliment. It happened because Darcy ended the conversation without giving Nick opportunity to respond the compliment.

From the findings, it was found that Darcy as a main female superior character in the film tended to give compliment on skills or abilities toward Nick because she wanted to give a reward or to appreciate Nick's effort in 
doing his job, concerning that Nick was Darcy's employee. Besides, as the boss, Darcy also wanted to encourage the employee to do better and better in working. The situation above happened since the setting and the topic of the conversation was talking about their job. It means that there was no personal experience in that conversation. Moreover, the topic and setting were formal and usually the communication happened at work. Overall, it shows clearly that since almost all of the topics and the settings were formal, social status became an important factor that influenced the way Darcy as female superior gave compliment toward Nick in order to give him reward or to encourage him.

However, if the topic was talking about an informal thing and especially involving the personal feeling, the reason why Darcy gave compliments toward Nick would be different. In those conversations, Darcy gave compliments toward Nick because she wanted to emphasize her agreement toward Nick's opinion. Darcy felt that Nick always thought in the same way as she did. It means that social status would not be a significant influence anymore when the relationship between man and woman turned to be a lover. In other words, the romantic relationship between Nick and Darcy became a significant influence for Darcy in giving compliments in order to show that she had feeling on Nick.

Besides Compliment on Skills/Abilities, there was Compliment on Personality produced by Darcy as female superior to Nick as male subordinate. Compliments on someone's personality traits are mostly used when the topic is informal. In that context, this type of compliment is used more to adore someone on the personality or behavior. The social status influenced the way Darcy gave compliments on Nick's personality traits because Darcy as female superior wanted to keep a distance with his employee who had lower status than her.

Compliments on Skills/Abilities were mostly used by Darcy because it was easier for Darcy to utter this kind of compliments in order to give a reward for her employee's achievement or to encourage the employee. On the other hand, Compliment on Personality Traits was lesser than Compliment on Skills/Abilities. Darcy's social status as female superior made her keep a distance with Nick as her employee who had lower status than she did. Besides, Darcy had to be professional. However, social status did not always become a determining factor in giving compliment as it was reflected in the film. The other factor that influenced the way Darcy gave compliments was the personal feeling or the relationship. It became easier 
for Darcy as female superior to give compliments toward Nick as male subordinate when their relationship was close. It means that social status becomes an influence factor when the participant could keep their relationship as professional as possible without involving the personal feeling.

There were also types of compliments which got zero (0). The types of compliments that were not found were Compliment on Appearance and Compliment on Possessions. Darcy never gave Nick Compliment on Appearance because the situation where both of them were involved into conversation was about their work and achievement. So, there was almost no chance for them to talk about the appearance especially to give Compliment on Appearance. Furthermore, Compliment on Appearance and Compliment on Possessions were found zero because the context of the movie did not support the main characters to produce those compliments.

Besides, it was found that the kinds of compliment responses produced by Nick as male subordinate were Appreciation Token, Comment History, Return and No Acknowledgement. Nick as male subordinate tended to give No Acknowledgement response toward Darcy's compliment. The reason was because Nick as a male hardly accepted compliments because he wanted to avoid self praise. Moreover, Nick gave no response to the compliments produced by Darcy because the conversation ended without giving Nick opportunity to respond to the compliment.

Return responses were used by Nick because he wanted to establish balance between Darcy and him by accepting the compliments. It indicated that the personal feeling happened among both of them. Appreciation Token appeared with the less number of percentages because the compliment which was responded by Appreciation Token was aimed only to support the context on the conversation and to make the conversation run smoothly. Nick responded only by saying "Yeah" because the compliment was not really important for him. The important one was the topic that Nick and Darcy were talking about, that was, control top panty hose. However, Comment History appeared as frequent as Appreciation Token because Nick did not want to get too private with Darcy. He appreciated the relationship with Darcy that had already been formed since the first time. 


\section{CONCLUSION}

From the findings and the analysis, it could be figured out that social status and gender did not always influence the way Darcy as a female superior character gave compliments toward Nick as a male subordinate character. The social status existed in the work communication had influenced the way Darcy complimented toward Nick when she could keep the relationship as professional as possible. Besides, personal feeling was the one that influenced the way Darcy complimented when the relationship between them (Nick and Darcy) was getting closer and closer.

Furthermore, social status and gender did not influence the way Nick responded the compliment. In the film, it was found that the conversation ending without giving Nick a chance to respond the compliment. Moreover, the compliments did not influence the way Nick gave compliment responses. Each compliment produced, responded with different types of compliments. The way Nick gave responses depended on the context and situation of the conversation. However, according to the tendencies of male subordinate in responding the compliment, it could be concluded that male hardly accepts compliments because he wants to avoid self praise.

Hopefully, this research would give another contribution in understanding the compliments and the compliment responses, especially in the conversation between male subordinate and female superior. It is also expected that this research would be useful for further research in compliments and compliment responses in different contexts and situations.

\section{REFERENCES}

Coates, J. (1986). Women, men and language: A sociolinguistic account of sex differences in language. London: Longman.

Holmes, J., \& Brown, D. (1987). World's culture about compliment. Cambridge: Cambridge University Press.

Herbert, R. K. (1990). Sex- based differences in compliment behavior. Language in Societ,. 19, 201- 224.

Ibrahim, J., \& Riyanto, T. J. (2000). A sociolinguistic study of compliment responses among Americans and Indonesians and its implications for teaching English. k@ta Journal, 1(2), 21-30. 
Tannen, D. (1991). You just don't understand. USA: Mc Graw Hill. What Women Want Transcript. Retrieved July 2, 2005, from http://blake.prohosting. com/bamzone/whatwomenwant.txt 